\title{
Awake craniotomy for vestibular schwannoma
}

\author{
Morten Lund-Johansen ${ }^{1}$ (if
}

Received: 25 May 2017 / Accepted: 31 May 2017 /Published online: 14 June 2017

(C) Springer-Verlag GmbH Austria 2017

"This will never work".

Cardiologist Spencer King (later to become president of the American College of Cardiology) commenting in 1977 on Andreas Gruentzig's poster "Experimental percutaneous dilatation of coronary artery stenoses".

During my years as a resident, laminectomy for cervical spondylosis with myelopathy was done in local anaesthesia in several departments in Norway. A few leading surgeons had once witnessed a single case where a patient woke up from general anaesthesia being tetraplegic. They concluded that it would be less risky if the procedure was done on awake patients, who, admittedly, sometimes reported Lhermitte phenomena if an instrument was introduced into a narrowed spinal canal. The practice was forwarded to us residents, but it has since been abandoned. The concept of reducing the risk of neurological damage by keeping patients awake during neurosurgery, however, has not.

Awake craniotomy has become common practice in surgery for low grade gliomas involving eloquent areas. Integrating cortical mapping, functional magnetic resonance imaging and neuronavigation enable us to do resections adjacent to critical areas [3, 7]. Provided careful preoperative and perioperative counselling is given, the procedure is feasible in many patients [5]. Recently, even aneurysm surgery has been done in local anaesthesia [1]. The authors reported that the procedure was tolerated, and that neurophysiological and

Morten Lund-Johansen

mljo@helse-bergen.no

1 Haukeland University Hospital, Bergen, Norway clinical monitoring led to clip repositioning in several patients who might otherwise have developed deficits.

In the present issue of Acta Neurochirurgica, Shinoura and colleagues [9] report, as a first, awake craniotomy for a series of eight patients operated on for vestibular schwannoma. They managed to save some hearing in all, and even improved it in one patient. There were no new facial deficits. The authors demonstrate that because they could communicate with the patient, deficits in facial function and hearing could be detected early during surgery and thereby prevented because the patient could communicate. If a deficit occurred, the surgeons paused resection and either continued if the deficit resolved or terminated it if it persisted. Hence they managed to preserve function. Although this is commendable, there are concerns. First, surgery for large vestibular schwannoma is time-consuming. The mean operating time was $6 \mathrm{~h}$. Even if the patients were asleep during opening and closure, they were kept awake in head fixation and park-bench position for several hours. This burden has to be considerable, whatever precautions are made. Second, the surgeons chose a very conservative resection policy, performing subtotal resection in most cases. This may call for close follow-up and many of these patients may be expected to experience a regrowth of their tumour, requiring additional treatment [6]. One may assume that the smaller the remnant, the less risk of recurrence. The strategy of doing near-total resection, leaving a very thin tumour remnant on the facial nerve is gaining increasing support, as this may lead to better facial nerve outcomes; the remnant grows slowly or not at all, and radiosurgery may stop further growth $[2,8,10]$. Near-total resection may, however, increase the risk of damage to the cochlear nerve.

The authors argue that radiosurgery may produce longterm hearing loss, and that their own strategy of performing subtotal resection on awake patients may lead to better outcomes. This is debatable. Subtotal resection may lead to 
tumour recurrence and hearing loss later on, similar to what is reported for radiosurgery. One recently published strategy is to do a subtotal resection followed by radiosurgery $[4,8]$. It remains to be seen if any of the two strategies will gain widespread use. Innovations in medicine that later become standard practice may frequently gain harsh comments early on. An example is found in the famous quote above. Dr. Gruentzig's pioneering work on dogs led to the development of percutaneous transluminal coronary angioplasty. One should be careful when raising strong opinions on new ideas!

\section{References}

1. Abdulrauf SI, Vuong P, Patel R, Sampath R, Ashour AM, Germany LM, Lebovitz J, Brunson C, Nijjar Y, Dryden JK, Khan MQ, Stefan MG, Wiley E, Cleary RT, Reis C, Walsh J, Buchanan P (2016) "Awake" clipping of cerebral aneurysms: report of initial series. J Neurosurg 21:1-8

2. Bailo M, Boari N, Gagliardi F, Franzin A, Piloni M, Spina A, Gemma M, Vecchio AD, Bolognesi A, Mortini P (2016) Gamma knife radiosurgery for residual and recurrent vestibular schwannomas after previous surgery: clinical results in a series of 90 patients and review of the literature. World Neurosurg 98:60-72

3. Ghinda D, Zhang N, Lu J, Yao CJ, Yuan S, Wu JS (2016) Contribution of combined intraoperative electrophysiological investigation with 3 -T intraoperative MRI for awake cerebral glioma surgery: comprehensive review of the clinical implications and radiological outcomes. Neurosurg Focus 40:E14

4. Iwai Y, Ishibashi K, Watanabe Y, Uemura G, Yamanaka K (2015) Functional preservation after planned partial resection followed by gamma knife radiosurgery for large vestibular schwannomas. World Neurosurg 84:292-300

5. Milian M, Tatagiba M, Feigl GC (2014) Patient response to awake craniotomy - a summary overview. Acta Neurochir (Wein) 156: $1063-1070$

6. Nakatomi H, Jacob JT, Carlson ML, Tanaka S, Tanaka M, Saito N, Lohse CM, Driscoll CLW, Link MJ (2017) Long-term risk of recurrence and regrowth after gross-total and subtotal resection of sporadic vestibular schwannoma. J Neurosurg 19:1-7

7. Paldor I, Drummond KJ, Awad M, Sufaro YZ, Kaye AH (2016) Is a wake-up call in order? Review of the evidence for awake craniotomy. J Clin Neurosci 23:1-7

8. Radwan H, Eisenberg MB, Sandberg Knisely JP, Ghaly MM, Schulder M (2016) Outcomes in patients with vestibular schwannoma after subtotal resection and adjuvant radiosurgery. Stereotact Funct Neurosurg 94:216-224

9. Shinoura N, Midorikawa A, Hiromitsu K, Saito S, Yamada R (2017) Preservation of hearing following awake surgery via the retrosigmoid approach for vestibular schwannomas in 8 consecutive patients. Acta Neurochir (Wein)

10. Syed MI, Wolf A, Ilan O, Hughes CO, Chung J, Tymianski M, Pothier DD, Rutka JA (2017) The behaviour of residual tumour after the intentional incomplete excision of a vestibular schwannoma: is it such a bad thing to leave some behind? Clin Otolaryngol 42:92-97 